\title{
Erratum to: Online petitions as actual protest practice in Russia and Germany: general and linguistic socio-cultural specific system-communicative characteristics
}

\author{
Larisa Rebrina $^{1^{*}}$, Nikolay Shamne ${ }^{2}$,Elena Eltanskaya $^{3}$ and Nina Wendt $^{4}$ \\ ${ }^{1}$ Volgograd State University, 400062 pr. Universitetskij 100, Volgograd, Russia \\ ${ }^{2}$ Volgograd State University, 400062 pr. Universitetskij 100, Volgograd, Russia \\ ${ }^{3}$ Volgograd State University, 400062 pr. Universitetskij 100, Volgograd, Russia \\ ${ }^{4}$ Language and Interpreting Institute Munich, Baierbrunner Straße 28, 81379 München
}

Original article:

SHS Web of Conferences (LLT Forum 2020)

Volume 88, 2020

International Scientific Forum "Issues of Modern Linguistics and the Study of Foreign Languages in the Era of Artificial Intelligence (dedicated to World Science Day for Peace and Development)" (LLT Forum 2020) https://doi.org/10.1051/shsconf/20208801005

The name of the author of the article Nina Wendti should be replaced by the following name: Nina Wendt 